\title{
Five-year-olds understand fair as equal in a mini-ultimatum game
}

\author{
Martina Wittig $^{\text {a,b }}$, Keith Jensen ${ }^{\mathrm{a}, \mathrm{c}, *}$, Michael Tomasello ${ }^{\mathrm{a}}$ \\ ${ }^{a}$ Department of Developmental and Comparative Psychology, Max Planck Institute for Evolutionary Anthropology, \\ D-04103 Leipzig, Germany \\ ${ }^{\mathrm{b}}$ Department of Developmental Psychology, Institute for Psychology, University of Kassel, D-34121 Kassel, Germany \\ ' School of Psychological Sciences, University of Manchester, Manchester M13 9PL, UK
}

\section{A R T I C L E I N F O}

\section{Article history:}

Received 14 February 2012

Revised 6 June 2013

\section{Keywords:}

Ultimatum game

Fairness

Inequity aversion

Punishment

Moral development

Social decision making

Norms

Sharing

\begin{abstract}
A B S T R A C T
In studies of children's resource distribution, it is almost always the case that "fair" means an equal amount for all. In the mini-ultimatum game, players are confronted with situations in which fair does not always mean equal, and so the recipient of an offer needs to take into account the alternatives the proposer had available to her or him. Because of its forced-choice design, the mini-ultimatum game measures sensitivity to unfair intentions in addition to unfair outcomes. In the current study, we gave a mini-ultimatum game to 5 -year-old children, allowing us to determine the nature of fairness sensitivity at a period after false belief awareness is typically passed and before formal schooling begins. The only situation in which responders rejected offers was when the proposer could have made an equal offer. But unlike adults, they did not employ more sophisticated notions of fairness that take into account the choices facing the proposer. Proposers, in their turn, were also not adult-like in that they had a very poor understanding that responders would reject unequal offers when an equal one was available. Thus, preschool children seem to understand "fair = equal" in this task, but not much more, and they are not yet skillful at anticipating what others will find fair beyond 50/50 splits.
\end{abstract}

(c) 2013 Elsevier Inc. All rights reserved.

\section{Introduction}

A central issue in the social life of humans is how resources get distributed. When sharing with others, the resource holder has her or his own interests in mind as well as a concern for how other people

\footnotetext{
* Corresponding author at: School of Psychological Sciences, University of Manchester, Manchester M13 9PL, UK.

E-mail address: keith.jensen@manchester.ac.uk (K. Jensen).
} 
will see her or him. Whether the resources are scarce or plentiful also makes a difference. Humans distribute valuable resources such as food much more widely among all group members, including nonkin, as our nearest primate relatives do (Gurven, 2004). Although even very young children (18month-olds) are very eager to help a struggling adult (e.g., retrieving out-of-reach objects or opening doors for them; Warneken \& Tomasello, 2006, 2007), the willingness to give up resources that they themselves want continues to develop until much later (e.g., Fehr, Bernhard, \& Rockenbach, 2008; Moore, 2009). In addition, the notion of what constitutes a "fair" distribution of resources changes during childhood. From an adult's point of view, fair generally means equal, but it can also mean that those who worked more should get more of "the pie" or that inequality may be acceptable depending on the intentions that led to this outcome. Thus, adults not only attend to their own gains and losses but also compare their outcomes with the gains and losses of other people, showing disadvantageous inequity aversion (aversion to having less than others) and advantageous inequity aversion (aversion to having more than others) (Loewenstein, Thompson, \& Bazerman, 1989; Fehr \& Schmidt, 1999; Bolton \& Ockenfels, 2000). Other models of fairness sensitivity propose that people are sensitive to the intentions underlying the outcomes (Charness \& Rabin, 2002; Dufwenberg \& Kirchsteiger, 2004; Levine, 1998; Rabin, 1993). It is likely that a combination of both aversion to outcome disparity and intentions leads to fairness sensitivity (Falk \& Fischbacher, 2006). Interestingly, even though children correctly (from the adult's point of view) indicate what would be considered fair, that does not necessarily mean that they also act on this knowledge (Damon, 1977). Understanding the nature of sociality requires an understanding of the components of fairness and how they develop during childhood. We focus on the ability to assess the intentions of others and the outcomes that arise in a bargaining game.

Developmental studies of resource distribution have examined the allocation behavior of children of different ages, either by letting the children freely distribute goods with a partner or among third parties or by letting them choose between two different allocations. It has been found that young preschool children, although they are not completely selfish when freely distributing goods, nevertheless favor themselves in such distributions much more than older children and adults do. Hook and Cook (1979) explained this as being due to logico-mathematical reasoning, that the transition from selfish to equal distributions follows the same pattern as the development of proportional reasoning in nonsocial contexts (see also Damon, 1975). For example, Rochat and colleagues (2009) found that 3- to 5year-old children were seldom generous but tended to hoard when asked to divide the goods between themselves and an adult experimenter, a tendency that seems to decrease with age. Furthermore, these 3- to 5-year-olds tended to be more egalitarian in their distributions when the outcomes did not affect themselves but rather a third party. Olson and Spelke (2008) showed, in another openchoice resource distribution paradigm, that even young children (31/2- and 4-year-olds) chose an equitable distribution of resources when one was available; they favored positively affiliated individuals only when an equal distribution was not available. In a forced-choice paradigm, Fehr and colleagues (2008) let children choose between equal amounts of sweets for themselves and a partner or, alternatively, different unequal distributions that favored either themselves or their partner. Their results suggest that younger children (3- to 5-year-olds) make choices benefiting the recipient only if it is not costly (i.e., if what the distributor gets is not affected).

As children reach school age at 5 or 6 years, they begin to distribute resources much more fairly, with fair almost always meaning equally divided among all involved. Moore (2009) found that $4 \frac{1}{2}-$ to 6-year-old children even shared when it was costly (i.e., choosing one sticker for both themselves and a partner vs. two stickers for themselves), but the children differentiated between the recipients; they behaved prosocially toward a friend and a stranger but not toward a nonfriend. On the other hand, when an unequal distribution was randomly set by the experimenter, advantaged 3- to 5year-old children were not likely to spontaneously share their resources with a partner but would do so if the partner requested it (Birch \& Billmann, 1986).

However, in all of the resource distribution studies, it is not clear what exactly children think fair is. They could be distributing items equally among all participants on the basis of simple mathematical rules, as influenced by adult norms that they have heard and experienced to the effect that "everyone should get an equal amount." But sometimes nonequal distributions are also fair, or else as fair as can be, given the constraints of the situation. In studies with adults, economic games are often used to pin down more precisely how adults respond to various distributional (division of the pie) problems (for 
an overview, see Camerer, 2003). For example, in the dictator game, one individual divides a resource with a second individual, who has no influence on the process (Camerer \& Thaler, 1995). Adults typically make offers of 20 to $30 \%$. Although this does not appear to be particularly fair, it is in fact surprising to economists because theoretical predictions based on rational self-interest would predict offering nothing.

To induce adults to make equal divisions between themselves and a random anonymous individual, the recipient needs to be given some power. This is the case in the ultimatum game (Güth, Schmittberger, \& Schwarze, 1982). The ultimatum game involves two players who are faced with the following problem. The first player, the proposer, is asked to divide an amount of goods (typically money) between the proposer and a second player, the responder. The responder then has two options: accept the proposed allocation or reject it. In the latter case, both players receive nothing, but if the responder accepts the proposal, both take home the proposed division. According to economic models based on self-interest (i.e., trying to maximize personal gains), responders should accept any nonzero offer and, therefore, proposers should always propose the smallest possible amount because for the responder something is better than nothing at all. Experimental findings in adults stand in stark contrast to this assumption. The most common offer by adult proposers is an even split, and responders reject offers below 20\% of the initial amount roughly half of the time (Camerer, 2003). Making an even-or fair-proposal is indeed a rational (self-interested) behavior on the part of proposers because they should take responders' perspective into account (assuming responders are not rational in the standard economic sense) and make an offer that is not likely to be rejected (Hardy-Vallée \& Thagard, 2008), although this still begs the question as to why responders, in one-shot anonymous interactions, reject anything at all. The suggestion is that in the real world, people make "optimal" offers, that is, those that have a high probability of being accepted while still giving a high payoff to the proposer (Harbaugh, Krause, \& Vesterlund, 2007). Presumably, both the proposer's and responder's behavior relies on what they consider to be a fair or justified distribution, sometimes influenced by general cultural norms (Henrich et al., 2005).

There recently have been a handful of studies using the ultimatum game to test inequity aversion in children. Harbaugh and colleagues (2007) used verbal response measures to test 8- to 18-year-old children in ultimatum games in group (classroom) settings and found that they behaved similarly to adults, with the younger children being more sensitive to the responses to their prior actions. A study of 5- to 10-year-old children measured choices and satisfaction in making these and found that the younger children were more selfish and that the older children shared more, and reported being happier as a result, at 9 or 10 years (Kogut 2012). A functional magnetic resonance imaging (fMRI) study of children from 6 to 14 years of age found that strategic behavior (i.e., more generous offers by proposers when faced with a risk of rejection) increased with age and that this was due to a decrease in impulsivity that was related to development of the left dorsolateral prefrontal cortex (Steinbeis, Bernhardt, \& Singer, 2012). Using a nonverbal choice task that is more suited to younger participants, Takagishi, Kameshima, Schug, Koizumi, and Yamagishi (2010) found that children between 4 and 6 years of age make more generous offers if they show false belief understanding (see also Sally \& Hill, 2006). However, in that study, even children who did not pass the false belief task quite often proposed fair offers such as 50/50 splits.

As Falk and Fischbacher (2006) pointed out, two types of fairness considerations are at work when playing the ultimatum game: outcome-based fairness, in which one compares one's own gains and losses relative to those of others, and intention-based fairness, in which one also takes into account the motives lying behind the outcomes. A reduced form of the ultimatum game, the mini-ultimatum game, directly addresses these two possibilities (Falk, Fehr, \& Fischbacher, 2003). The simple idea that fair equates with equal does not always apply. The mini-ultimatum game probes the context of unfair offers; by pairing an disadvantageous allocation with different alternatives, one can specifically investigate how responders react to unfair offers depending on the intentions with which they are given. In the original game (Falk et al., 2003), two allocations of experimental points (exchanged for money at the end) are presented as a forced choice. Across four games, one of the outcomes was always unfair, namely 8 points for the proposer and 2 points for the responder (a division that is routinely rejected). The alternatives were 5 points for both players (equal outcome: $5 / 5$ game), 2 points for the proposer and 8 points for the responder (generous outcome: $2 / 8$ game), 8 points for the proposer and 2 points 
for the responder (unfair outcome: $8 / 2$ game), and 10 points for the proposer and 0 points for the responder (hyper-unfair outcome: 10/0 game ${ }^{1}$ ). Adult responders took into account the options the other person had available when she or he proposed a particular division of resources, including ones that were not equal (Falk et al., 2003; Sutter, 2007). When responders were faced with an unfair offer when the proposer could have been fair (5/5 game), they reliably rejected it. An unfair offer (based on outcomes alone) is judged less harshly and rejected by fewer responders when the proposer had no better alternatives (2/8 and 8/2 games). Proposers take responder's perspective into account in that they tend to choose the fairest possible alternative and never make offers of zero (which one can expect every responder to reject).

The only studies employing the mini-ultimatum game with children focused on school-age children and adolescents using verbal response measures (after 7 years of age: Güroglu, van den Bos, \& Crone, 2009; Sutter, 2007) and found that, similar to adult responders, school-age children clearly distinguish between the same absolute offer in different situations and, therefore, seem to take both the intentions of their partner and the absolute outcomes into account; they reject unequal offers more often when the partner could have made an equal offer than when the partner had a more generous alternative, no alternative, or an even worse option. Proposers also take the perspective of their partner into account in that they avoid making unfair offers if possible and if it is not too costly to do so (i.e., generous offers are chosen less often than equal offers). However, the children in Sutter's (2007) study also occasionally behaved selfishly by offering zero in approximately $15 \%$ of the cases.

To determine the role of intentions and outcome differences in making fairness decisions, we presented the mini-ultimatum game to 5 -year-old children using an apparatus that has been successfully applied to a nonlinguistic species (chimpanzees; Jensen, Call, \& Tomasello, 2007). Thus, we used as little verbal instruction as possible and did not require verbal responses. Because we were interested in which alternatives proposers would choose and how responders would react to unfair offers, we tested pairs of children in a nonanonymous setup because this provides a much more natural setup for the children. It is plausible to assume that children acquire fairness understanding in face-to-face interactions with their parents and peers. Because children even younger than 5 years seem to have some understanding of their partner's desires (Rakoczy, Warneken, \& Tomasello, 2007), 5-year-olds should also be able to take their partner's desires into account and, thus, make offers similar to those of older children and adults, that is, equal offers if possible and no zero offers. Furthermore, children at a very early age recognize that other individuals have intentions (e.g., Carpenter, Akhtar, \& Tomasello, 1998; Meltzoff, 1995); by 5 years of age, they can use proportions, as well as absolute quantities, in making equity judgments (McCrink, Bloom, \& Santos, 2010), and typically at this age they can recognize that others can have beliefs that differ from their own (Wellman, Cross, \& Watson, 2001). Responders should reject offers of zero, and they should show a similar rejection pattern as older children and adults if they understand intentionality and differential outcomes. That is, they should routinely reject unfair (3/1) offers in the $2 / 2$ game when there is a fair alternative and then show a decline in frequency of rejection of $3 / 1$ offers across the other three games $(1 / 3>3 / 1>4 / 0)$ as the degree of unfairness compared with the alternative decreases.

\section{Method}

\section{Participants}

Children whose parents had previously given consent were recruited from, and tested in, various kindergartens in a medium-sized city in Germany. A total of 645 -year-olds took part in this study ( 32 girls and 32 boys), which made up 32 same-sex pairs. The children's ages ranged from 5;0 (years;months) to $5 ; 5$, with a mean age of $5 ; 2(S D=1.4$ months). Although the proposer and responder came from the same kindergarten, they were always from different classes. Thus, they had seen each other

\footnotetext{
${ }^{1}$ In ultimatum game terminology, the number before the slash represents the proposer's portion and the number after the slash represents the responder's portion.
} 
before but did not know each other as well as if they had come from the same class. The children were from broadly middle-class backgrounds.

\section{Materials}

The setup consisted of the apparatus and two chairs with cardboard boxes mounted at the backs. One child would sit in a chair on the left side of the apparatus (proposer's position), and the other child would sit on the right (responder's position). The children used the boxes on the backs of their chairs to store the rewards they accumulated. The two positions were delineated by a Plexiglas partition and a translucent curtain, allowing the children to see each other but preventing them from reaching to the other's side of the apparatus.

The apparatus was a wooden box with transparent Plexiglas panels on the front and top $(60 \mathrm{~cm}$ wide $\times 40 \mathrm{~cm}$ high $\times 40 \mathrm{~cm}$ deep; Fig. 1). From the children's perspective, the apparatus looked like a chest of drawers with a clear face. There were two wooden trays, one at the top and one at the bottom, each with two clear Plexiglas dishes attached to them, one on the proposer's side and one on the responder's side. Those dishes held the rewards. The front panel prevented children from being able to reach the dishes until one of the trays had been pulled completely to the front of the box. Each tray had a rope on the proposer's side and a rod on the responder's side. The rods were inside the apparatus, behind the clear front panel, at the start of testing.

Haribo gummy bears were used as rewards. Pilot work on this project showed that 5-year-old children enjoy receiving gummy bears and, in fact, show a preference for these over other food items and
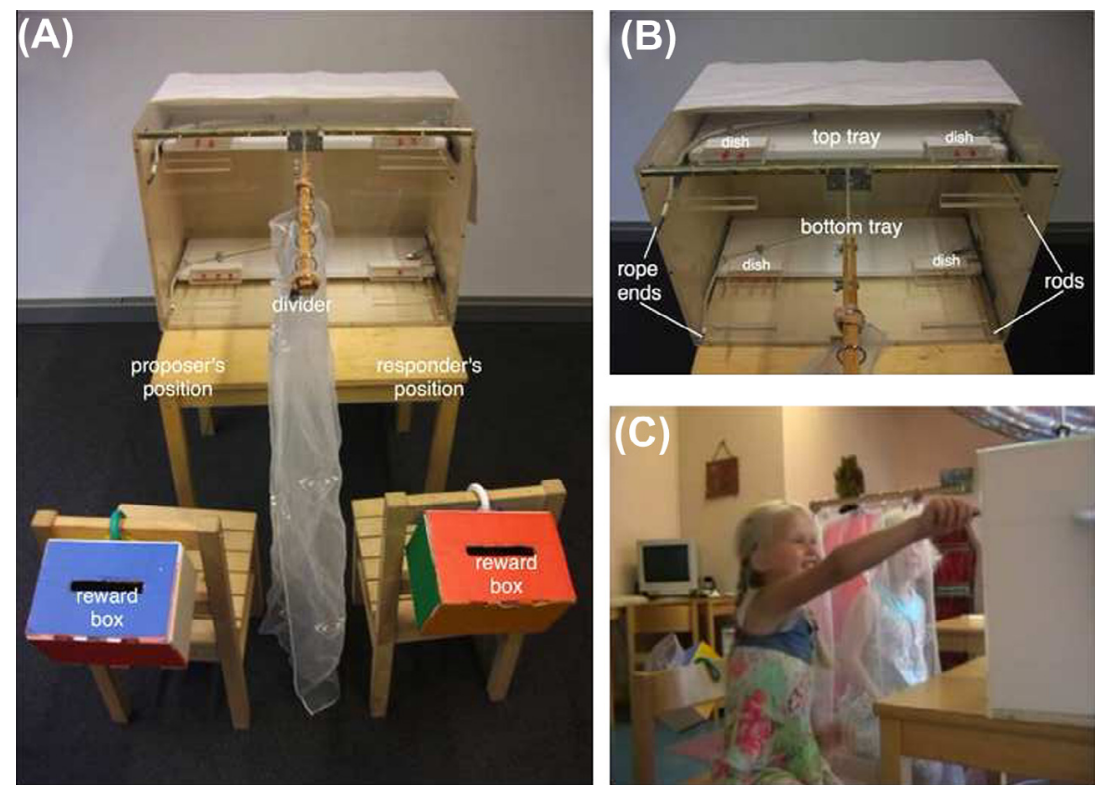

Fig. 1. Experimental setup. (A) Children would sit on the left (proposer's position) or the right (responder's position). On the backs of each chair were cardboard boxes for holding rewards. A divider made of Plexiglas and a translucent curtain demarcated the two positions. (B) The apparatus was a wooden box with a transparent Plexiglas top and front panel. The children could see the two trays (top and bottom) and the four Plexiglas reward dishes (two on each tray, with dishes on the left being accessible from the proposer's position and dishes on the right being accessible from the responder's position). Either tray could be pulled by one of the rope ends in the proposer's position, resulting in the other rope end moving out of reach inside the box (in this image, the top tray has been pulled). A rod on the pulled tray would then be within reach from the responder's position; the rod on the other tray would remain out of reach. The rod could be used to pull the tray completely, resulting in the two dishes on it coming out of the box so that the contents could be collected by both children, or pushed back inside the box, resulting in neither dish being accessible. (C) Here, a responder pulls the rod while the proposer watches. 
nonfood items such as stickers (Warneken, Lohse, Melis, \& Tomasello, 2011). In no case did a child indicate a dislike of gummy bears. However, because children might show preferences for different colors/flavors, we used four of the five available colors/flavors (we did not use white ones because these might have been harder to see on the trays), meaning that we used each color/flavor once across the four conditions. Within each condition, all four trays were baited with the same colors/flavors to avoid any confounding effects of preference.

\section{Procedure}

The experiment was run across two separate days for each participant. The first day was used to familiarize the children individually with the apparatus. Testing, including control trials, took place on the second day. In brief, children were familiarized and tested across 2 days. On the first day, children were introduced to the apparatus as either proposers or responders. Proposers learned that they could pull a rope causing one of the two trays holding gummy bears to move forward such that a rod became accessible on the responder's side; responders learned that they could pull the rod to bring the gummy bears within reach or push the rod back in to make the gummy bears inaccessible. On the following testing day, proposers and responders were tested in pairs (test) and alone (no-partner control); the order was counterbalanced across participants. In the test, proposers could choose one of two trays and responders could accept (pull) or reject (push) these offers. To test task comprehension, proposers and responders were tested alone in no-partner controls that resembled familiarization. The procedures are described in further detail below.

\section{Familiarization}

Every child was individually shown how the apparatus functioned. The children were randomly assigned to one of the two roles, proposer or responder. They were alone when introduced to the apparatus. First, the experimenter focused the attention of the child on the top tray, pointing out that there were two dishes, one on each side of the tray, a rope that could be pulled, and a rod that could not be pulled just yet. The same was then done for the bottom tray. At this point, there were no rewards in the dishes. After this, the proposer and responder familiarization procedures differed.

Proposer familiarization. The proposer sat in the left-hand chair, and the experimenter showed the proposer how she or he could use the apparatus from the proposer's side but could not access anything on the responder's side. The experimenter sat in the responder's chair to demonstrate. She guided the child through all of the steps needed to obtain gummy bears on both the top and bottom trays and also showed what happened when the rod was not pulled but instead pushed back in.

After this, the proposer was given 4 trials with gummy bears in the dishes. (See Table 1 for the reward distributions.) There were four different distributions referred to as "games." The payoff (reward) structure was similar to the one used by Falk and colleagues (2003), Sutter (2007), and Jensen and colleagues (2007). Whereas those studies (using money, stickers, and raisins as rewards, respectively) used quantities of 10 for each choice $(8 / 2,2 / 8$, and $10 / 0)$, we used a total of 4 gummy bears per tray to reduce the number of rewards to be counted. The ratios were similar but not exactly the same (75/25\% instead of $80 / 20 \%$ ). The experimenter put gummy bears in all dishes on both the top and bottom trays. The child was asked to count the gummy bears in each dish. The experimenter reminded the child that she or he could reach only the dish on the proposer's side but that the child could collect the gummy bears there and put them in the box at the back of her or his chair, whereas the experimenter would take the gummy bears from the other dish and put them back in the bag. The child indicated her or his choice of tray (e.g., by saying, "I'm going to pull that one") and then pulled the rope attached to that tray. Pulling that end of the rope resulted in the tray moving halfway forward and the other rope end being pulled inside the apparatus and out of reach; when the tray moved forward, the rod for that tray emerged from the box on the responder's side. The experimenter then pulled the rod so that the child could access her or his dish and collect the gummy bears; the gummy bears on the responder's side were removed and put away. The experimenter clearly indicated that no one would get these. In 4 trials, counterbalanced for order across participants, one tray (counterbalanced for top and bottom) was baited with 3 gummy bears in the proposer's dish and 1 gummy bear 
Table 1

Distribution of gummy bears, proposer choices, and responder reactions in the test condition.

\begin{tabular}{|c|c|c|}
\hline \multirow[t]{2}{*}{ Game } & \multicolumn{2}{|l|}{ Payoffs } \\
\hline & Proposer & Responder \\
\hline \multirow[t]{2}{*}{$2 / 2$} & 3 & 1 \\
\hline & $\begin{array}{c}2 \\
0\end{array}$ & $\stackrel{2}{0}$ \\
\hline \multirow[t]{2}{*}{$1 / 3$} & 3 & 1 \\
\hline & $\begin{array}{l}1 \\
0\end{array}$ & 3 \\
\hline \multirow[t]{2}{*}{$3 / 1$} & 3 & 1 \\
\hline & 3 & 1 \\
\hline \multirow[t]{2}{*}{$4 / 0$} & 3 & 1 \\
\hline & 4 & 0 \\
\hline
\end{tabular}

Note: Position (top and bottom) was randomized; here, for the sake of simplicity, the $3 / 1$ choice (which was constant in all games) is shown in the top tray. There is no difference between the two trays in the 3/1 game. Order of the games (reward distributions) was randomized. The same distribution was used in the familiarization, test and no-partner control trials.

in the responder's dish (3/1), and the other tray had a one of four alternate distributions $(2 / 2,1 / 3,3 / 1$, or $4 / 0$; see Table 1 ). Adopting the reasonable assumption that children had a preference for larger quantities of reward over smaller ones, if a child failed to pull the tray with the most gummy bears (or could not justify her or his choice), the trial was repeated (at most twice), but the experimenter did not comment on whether this was right or wrong; she only asked why that tray was chosen. The child was not told to get as many gummy bears as possible, and any justification for the choice was acceptable. Any initial choice of the lesser amount was taken to be a failure to understand the mechanics of the apparatus and not a preference for smaller quantities of food.

Responder familiarization. In the familiarization for the responder, the child sat in the chair on the right and the experimenter took her place in the proposer's position on the left. The child was first shown how the apparatus worked, as described above.

When gummy bears were introduced, the child was asked to indicate her or his preference for the top or bottom tray, and the experimenter pulled the corresponding rope. The child would then pull the rod that was now within reach to bring the gummy bears on that tray outside of the apparatus. The child collected these and put them in her or his box. The responder was faced with the same four different distributions of gummy bears as the proposer (Table 1), getting the amount on the right of the tray (note that this was usually less than the amount on the proposer's side). In addition, the responder received 2 "accident" trials in which the experimenter "accidentally" pulled the wrong rope by looking away from the apparatus in a distracted manner (distributions were $3 / 1$ vs. $1 / 3$ and 3/1 vs. $4 / 0)$. The responder could then indicate that she or he did not get the tray she or he wanted $(1 / 3$ would be preferable in the former case, and 3/1 would be preferable in the latter case) and would push the rod back in. These trials gave the child experience with rejecting outcomes she or he did not want. Once the responder rejected the tray, the experimenter corrected herself by resetting the apparatus and pulling the rope the child had requested. These trials were presented at random with the standard trials except that they were never the first or last trials in the familiarization session. 
Test

Testing took place between 1 and 6 days after the familiarization (the average interval was $\sim 2$ days). On the testing day, the experimenter returned to the kindergarten. Children were randomly paired with a same-sex partner who had been trained in the alternate role. Both children were taken together by the experimenter to the room in which the apparatus was set up. The children were told that before doing this together, the experimenter wanted each child to individually show her whether she or he remembered how to use the apparatus. One child then entered the test room with the experimenter while the other child stayed outside with an assistant. The experimenter asked the child what she or he remembered and asked the child to show her. Proposers would pull a rope of one of the trays (there were no gummy bears in the dishes) and state that the experimenter could pull the rod. Responders would say the experimenter could pull a rope, which she did, and then the child would pull the rod. Because pulling the rod was the typical response, the experimenter would ask what else could be done with the rod. If the child spontaneously answered "push it back," this was also demonstrated. If the child did not verbalize this, the experimenter asked again what else could be done with the rod in case the child does not want what is in that dish. No further prompting was needed.

Once refamiliarization was done, the second child was brought into the room and sat down at her or his position. The experimenter told the two children that they would now use the apparatus with a partner and that the experimenter would leave the room once everything was ready. She reminded them that the child on the left would make the first choice between the two trays and that the child on the right could then pull the rod or push it back in. We never used the terms "proposer," "responder," "game," "share," "reject," "fair," and "punish" with the children to avoid priming them with role expectations. The experimenter distributed the gummy bears in the dishes with the same quantities as in the familiarization (Table 1) and told the children to wait to make their choices until she left the room and to call her when they were done. This was done to avoid social desirability biases based on presumed experimenter expectations. When the experimenter returned to the room to reset the apparatus and begin a new trial, she did not make eye contact with the children, did not comment on the choices, and removed the remaining gummy bears in a disinterested fashion. Each pair of children played four games ( 4 trials); the order of the games was counterbalanced across participants, and the tray holding the largest amount for the proposer was counterbalanced within participants (i.e., 2 on the top, 1 on the bottom, or vice versa; there was no choice for the $3 / 1$ game).

\section{No-partner control}

On the same day as the test, children were given a no-partner control in which they played the mini-ultimatum game without a partner, with order (test/control) counterbalanced across pairs of participants. The purpose of the control was to discriminate between choices that had social effects (other-regarding preferences) and those that only affected the children themselves. The reward distributions were the same as in the familiarization and test. For proposers, this meant that the experimenter would pull the rod each time the child pulled a tray; for responders, this meant that the experimenter would pull the tray they indicated (e.g., by pointing) plus 1 extra trial in which she pulled the wrong rope (rejection probe). The experimenter was uninvolved and never "received" any of the rewards. Gummy bears on the partner's side were removed by the experimenter and put in a bag; it was clearly indicated that no one got these. The experimenter never commented on the children's choices, and trials were never repeated.

\section{Analyses}

All trials were videotaped and coded from video. A random sample of $25 \%$ of the no-partner control and test conditions was coded by a second observer, who was blind to the experimental design and question, for the choice of tray (top or bottom) by the first child and whether the second child pushed the tray back in or pulled it out. Reliability for both was very high $(\kappa=.98)$.

Nonparametric tests (Cochran's $Q$ and McNemar's change test) were used in all of the analyses because we obtained binomial data both for the proposer's offers and for the responder's reactions. Because the McNemar test excludes tied observations from the sample, the sample size is sometimes smaller than 32 . For example, if a proposer chooses the $3 / 1$ option in the $2 / 2$ game in both the 
no-partner control and test conditions, those data are excluded. All tests were two-tailed, and significance was set at .05. To test for overall rejection rates and carryover effects, we also used the RSWMV (related samples with missing values) test (Mundry, 1999). This is a repeated samples test that uses permutations to accommodate missing values, and it has more power than a Friedman's one-way analysis of variance (ANOVA), making it suitable for a within-participants analysis of order effects. Chi-square and binomial tests for preference tests and effects of verbal responses were used with significance based on the exact method.

\section{Results}

Analyses consider the behavior of proposers and responders separately.

\section{Proposers}

In the test condition, there was a trend in frequency with which children made $3 / 1$ offers across the three games in which there was an alternative $(2 / 2,1 / 3$, or $4 / 0$; Cochran's $Q=5.36, N=32, d f=2$, $p=.075)$. That is, there was a tendency for children to vary their proposals depending on the game they were playing, with fewer $3 / 1$ offers being made in the $4 / 0$ game than in the $2 / 2$ and $1 / 3$ games (Fig. 2). There was no effect of the order in which the games were played (Cochran's $Q=2.677, d f=3$, $p=.478$ ). Furthermore, there were no carryover effects, meaning that a choice in one trial (game) had no effect on choices in the subsequent trials ( $R S W M V$ test $=23.244, p=.814$, number of permutations $=1000$, positions of missing values kept fixed).

To determine whether proposers adjusted their choices in response to another child, we compared their choices in the test with the corresponding game in the no-partner control. We first examined the effect of order of test and no-partner control on proposer choices. There was no effect on proposer offers in the test (Mann-Whitney $U$ test, $z=1.632, n=16$ for each group, $p=.138$ ). There was a trend for proposers who did the test before the control to make fewer mistakes in the no-partner control (Mann-Whitney $U$ test, $z=2.213, n=16$ for each group, $p=.073$ ). Because there were no significant differences between the two groups of children, we pooled the results for subsequent analyses. Results for the McNemar tests are presented as the number of children who made a different choice in the test and in the no-partner control; cases in which the same choice was made in both are excluded. In the $2 /$ 2 game, children chose the 3/1 option significantly less often in the test than in the no-partner control (McNemar test, $n_{2 / 2 \text { test }}=11, n_{2 / 2 \text { control }}=2, p=.022$ ). Even so, only $44 \%$ of proposers chose the equitable option in the $2 / 2$ game. In the $1 / 3$ game, there was a trend toward proposers choosing $3 / 1$ (the largest personal option) less often in the test than in the no-partner control (McNemar test, $n_{1 / 3}$ test $=9$, $n_{1 / 3 \text { control }}=2, p=.065$ ); they made more generous offers $38 \%$ of the time. In the $4 / 0$ game, children did

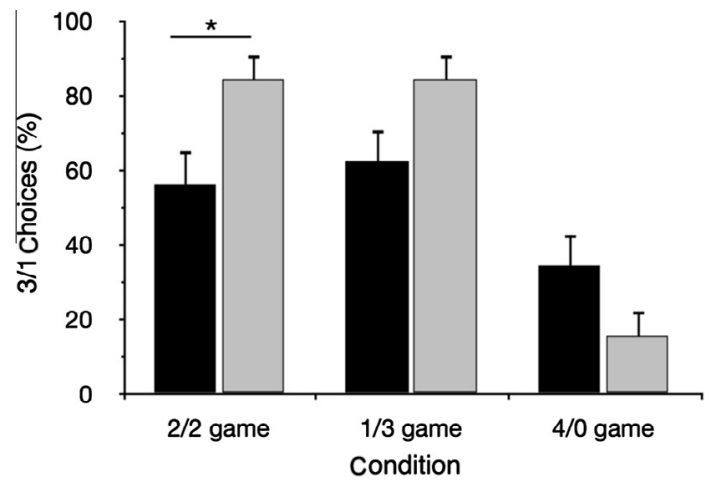

Fig. 2. Choice behavior (mean percentages of choices \pm standard errors) of proposers across the three games in which there was an alternative in the no-partner control and test conditions. Test conditions are shown by black bars, and controls are shown by light gray bars. An asterisk indicates a significant difference in the rate of 3/1 choices between no-partner control and test conditions. The 3/1 game was excluded from the graph because in this game there was no choice available. 
not choose 3/1 more often than in the no-partner control (McNemar test, $n_{4 / 0}$ test $=3, n_{4 / 0}$ control $=9, p=$ .146 ); the overall rate of $3 / 1$ choices in the $4 / 0$ game was rather low (34\%) considering this meant that $66 \%$ of proposers offered nothing to the responder. See Table 1 for an overview of the proposer's choices in the test condition. There were no clear individual differences; always making a generous offer was very rare (only 2 of 32 proposers always made an offer that was favorable for the responder in all games). More often, proposers chose the largest amount for themselves on at least 1 of the 3 trials $(1 / 3,2 / 2$, or $4 / 0, n=7), 2$ of the 3 trials $(n=17)$, or all 3 trials $(n=6)$. Girls and boys did not differ in their proposals.

In the no-partner control, proposers chose the largest amount available in all games in which there was an alternative. They preferred $4 / 0$ over $3 / 1$ in the $4 / 0$ game $\left(\chi^{2}=15.125, d f=1, p<.001\right)$, they preferred $3 / 1$ over $1 / 3$ in the $1 / 3$ game $\left(\chi^{2}=15.125, d f=1, p<.001\right)$, and they preferred $3 / 1$ over $2 / 2$ in the $2 / 2$ game $\left(\chi^{2}=15.125, d f=1, p<.001\right)$. There were no instances of position preference (i.e., choosing the top regardless of number of gummy bears) (See Table 2 ).

\section{Responders}

The analysis of responders' behavior focuses on the rejection rates of unfair offers in the test condition using a nonparametric related samples test (RSWMV test; Mundry, 1999). A comparison of test and no-partner control responses is not applicable, as it was for proposers, because responders did not encounter unfair divisions in the control. However, because it was possible that the order of presentation of test and no-partner control could have influenced willingness to accept or reject offers, we compared rejection rates of disadvantageous offers when the no-partner control preceded the test and vice versa; there was no effect of order (Mann-Whitney $U$ test, $z=1.048, n=14$ control first, $n=16$ test first, $p=.334$ ). Overall, the rejection rate of $3 / 1$ offers across the four games in the test was significant $(p=.011)$. Considering the rejections across the games, only the rejection rate of $3 / 1$ offers in the $2 / 2$ game differed from the rejection rates of the same offer in the other three games ( $2 / 2$ vs. $1 / 3$ game, $p=.048 ; 2 / 2$ vs. $3 / 1$ game, $p=.018 ; 2 / 2$ vs. $4 / 0$ game, $p=.003$ ).

To determine the degree to which responders rejected offers, we compared rejection rates with a baseline of always accepting offers, as in Jensen and colleagues (2007). The 2/2 game was the only game in which children rejected 3/1 offers significantly more than the baseline of always accepting (McNemar test for rejecting 3/1 in the 2/2 game, $n_{\text {reject }}=6, n_{\text {accept }}=0, p=.031$ ); in all other games, rejections of $3 / 1$ offers did not differ from the baseline (Table 1 ). The only other offer to be rejected above baseline was $4 / 0$, which was rejected $72 \%$ of the time (McNemar test, $4 / 0$ rejections vs. always accept, $\left.n_{\text {reject }}=12, n_{\text {accept }}=0, p<.001\right)$. Fig. 3 provides an overview of the rejection rates of all offers.

\section{Table 2}

Outcomes of proposer choices and responder rejection rates (\% of trials) in the 4 conditions of the mini-ultimatum game. Asterisks indicate percentage of rejections that differ significantly from null $(\mathrm{p}<0.05)$.

\begin{tabular}{lllll}
\hline \multirow{2}{*}{ Game } & Proposer offers (\%) & \multicolumn{2}{l}{ Payoffs } & Responder rejections (\%) \\
\cline { 3 - 5 } & & Proposer & Responder & \\
\hline $2 / 2$ & 56 & 3 & 1 & $33^{*}$ \\
& 44 & 2 & 2 & 0 \\
$3 / 3$ & 63 & 3 & 1 & 15 \\
$3 / 1$ & 37 & 1 & 3 & 13 \\
$4 / 0$ & 100 & 3 & 1 & 0 \\
& 34 & 3 & 1 & $71^{*}$
\end{tabular}

Note: Position (top and bottom) was randomized; here, for the sake of simplicity, the 3/1 choice (which was constant in all games) is shown in the top tray. There is no difference between the two trays in the 3/1 game. Order of the games (reward distributions) was randomized. The same distribution was used in the familiarization, test and no-partner control trials. Asterisks indicate percentage of rejections that differ significantly from null $(\mathrm{p}<0.05)$. 


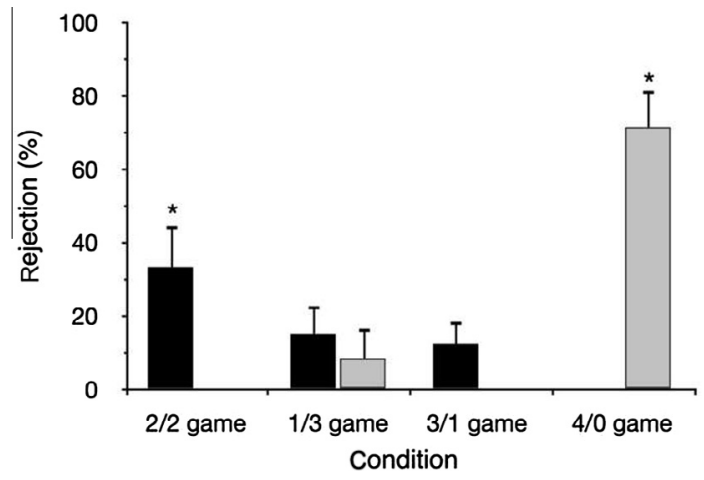

Fig. 3. Mean percentages ( \pm standard errors) of offers rejected by 5 -year-olds across the four test conditions (games). Rejections of $3 / 1$ offers are shown by black bars, and rejections of the alternates are shown by light gray bars. Each alternate offer corresponds to the game's name (e.g., $2 / 2$ in the $2 / 2$ game). Note that there was no alternate in the $3 / 1$ game. An asterisk denotes rejections that differ significantly $(p<.05)$ from null.

Responders showed a preference for the largest personal amounts, when given a choice, in the nopartner control, and they reliably rejected the wrong division (accident trials). They preferred 3/1 over $4 / 0$ in the $4 / 0$ game and never chose the zero option; they preferred $1 / 3$ over $3 / 1$ in the $1 / 3$ game, $\chi^{2}=28.125, d f=1, p<.001$; and they preferred $2 / 2$ over $3 / 1$ in the $2 / 2$ game, $\chi^{2}=28.125, d f=1$, $p<.001$. They also reliably rejected the undesired distribution in the rejection probe (McNemar's change test, $\left.n_{\text {accept }}=4, n_{\text {reject }}=12, p<.001\right)$. In all distributions (3/1 vs. $3 / 1$ excluded), they chose the tray with the largest amount of gummy bears ( 2 of the 32 responders chose a nonmaximizing tray once, and none of the children chose the zero option). Fully 26 of the 32 responders rejected the zero division made by the experimenter in the accident trials. That is, 26 children pushed the empty tray away and 6 children pulled the rod even when there was nothing in their dish. Of these 6 children, 2 suggested to the experimenter that she could reset the apparatus. In these cases, the experimenter did not comment and proceeded to the next trial.

\section{Verbal responses}

Children talked very little during testing. However, responders sometimes made requests to proposers by pointing to the preferred tray, reaching for it, touching the rod, and making a verbal request such as, "I want you to pull that tray", (35/128 trials). In the three games in which the proposer actually had choices (i.e., excluding the $3 / 1$ game), there were 30 trials in which the responder made a request; of these, the proposer chose the indicated tray in only 14 trials (47\% of the time), which is not different from choosing at chance (binomial test, $p=.855$ ). Proposers were no more generous whether responders verbally indicated their preference or not $\left(\chi^{2}=.915, d f=1, p=.374\right)$. When proposer choices matched responder requests (i.e., they were generous), none of the offers was rejected. However, when proposers did not choose the indicated option, responders reliably rejected 10 of 16 offers $\left(\chi^{2}=13.125, d f=1, p<.001\right)$. Although they also rejected undesired offers when they said nothing (14/ 42 trials, $\left.\chi^{2}=7.398, d f=1, p=.012\right)$, responders were nearly twice as likely to reject when their request was ignored (nonsignificant trend, $\chi^{2}=4.063, d f=1, p=.072$ ). Rejections were sometimes justified by responders with utterances such as, "I don't want that", and, "But then I only get one [none]." As for proposers, they only rarely told responders what to do (6/128 trials), and they never protested rejections made by responders. Other comments made by the children were mostly centered on stating how many gummy bears they had obtained.

\section{Discussion}

Overall, 5-year-old proposers behaved rather selfishly. In contrast to older children and adults (Falk et al., 2003; Sutter, 2007), fair or generous offers were less common among 5-year-olds. The most 
striking finding was the high amount of zero offers. Whereas adults in general do not choose to offer zero, presumably because they know that their partner would reject this, 5-year-old children chose the zero option in $65 \%$ of the cases and did so even when they had experienced a rejection of another such offer before. Still, older children of roughly 9 years chose the zero option approximately $15 \%$ of the time (Sutter, 2007). The failure to suppress one's initial desire to obtain all of the rewards can be explained by a lack of reflection about these outcomes. As a recent study by Blake and McAuliffe (2011) suggests, until approximately 8 years of age, children do not consider advantageously unequal distributions of candy as unfair.

Nevertheless, proposers in this study differed in their choice behavior depending on whether there was a partner; in the $2 / 2$ and $1 / 3$ games, they chose the $3 / 1$ option less when they were with a partner, suggesting that they adjusted their preferences for the responder, but only when faced with an equitable option. Only in the $4 / 0$ game did they not choose differently when with a partner as opposed to alone; that is, they did not adjust their choice of $4 / 0$ between the test and no-partner control conditions. The implication is that although they might have understood their partner's desires (i.e., having 1 gummy bear), the option of 4 gummy bears was too tempting. Interestingly, proposers did not behave more generously when the partner made a request; they made their choices regardless of the verbal response of the responder. This finding is in contrast to Brownell, Svetlova, and Nichols (2009), who found that 2-year-old children, but not 18-month-old children, chose a mutualistic option $(1 / 1)$ as opposed to a selfish option (1/0) more often when an adult experimenter expressed a desire for the food rewards than not. This difference might be due to the fact that in our study responders made explicit preferences for the choices they wanted proposers to make rather than just indicating a desire for the rewards; it may also be that children are less likely to comply with peers than with adults. These are questions that could be addressed in future studies.

The 5-year-old responders in this study reliably rejected offers of zero, thereby clearly indicating that zero is not an acceptable offer. They showed the highest rejection rate of unfair (3/1) offers when the proposer could have been fair $(2 / 2)$, they rejected less when the alternative for the proposer was generous $(1 / 3)$ and when there was no alternative at all (3/1), and they did not reject the unfair offer when the alternative would have been even more unfair (4/0). In contrast to the findings in older children and adults (Falk et al., 2003; Sutter, 2007), there was no difference in the rejection rates of unfair offers in the generous (1/3) and unfair (3/1) games. This suggests that their understanding of fairness is that both get equal amounts. Finer degrees of fairness considerations do not seem to play a role for 5-year-olds because they do not reliably reject unfair offers in the other contexts (when a generous alternative or no alternative was available to the proposer). That is to say, they do not seem to be sensitive to relative outcome disparities in the same way as adults are (e.g., as in Fehr \& Schmidt's [1999] model), nor do they appear to take the intentions of the proposer into account (as in Rabin's [1993] model and Falk \& Fischbacher's [2006] model). These findings are in line with the assumption of Fehr and colleagues (2008) that young children's fairness considerations present themselves as disadvantageous inequity aversion (see also Sutter, 2007). More precisely, in our study disadvantageous inequity aversion is only in response to departures from even splits. Requests appeared to serve as reliable signals, or commitment devices, in that responders were nearly twice as likely to refuse an offer that did not match their preferences than when they did not indicate a preference. This finding is consistent with "cheap talk" in which people are assumed to follow through on threats; however, contrary to results on adults (e.g., Farrell \& Rabin, 1996; Tingley \& Walter, 2011), the signals given by the children had no effect on proposers' choices. This may be because responders in our study did not verbalize threats or promises to reject; expressing a preference may be perceived as a weaker commitment device than stating a future course of action. The roles of commitment devices and cheap talk in strategic behavior in children warrant further research.

The lack of anonymity in the games cannot account for proposers' relatively selfish behavior because one would expect even more generous offers on behalf of proposers if their offers were not anonymous (Camerer, 2003). Instead, we provided them with repeated games with full knowledge of the partner's decision (although without role reversal to eliminate reciprocity). Recent findings indicate that being observed in experimental games has no effect on proposer offers and responder behavior (Barmettler, Fehr, \& Zehnder, 2012; Lamba \& Mace, 2010). No studies on children have been done with the full anonymity typical of experimental economics. Some, such as Fehr and colleagues (2008) and Moore (2009), have had children playing against hypothetical children but with the experimenter 
present. Future studies could directly address the role of anonymity by directly comparing participants with partners present or absent (but with experimenter present) and with full anonymity.

It seems to be the case that proposers had a much harder task to solve than responders. Whereas responders needed to weigh only what was being offered to them against what they could have had, proposers needed to take into account how the partner would react to their offer before making it. This seems to be especially difficult for them because proposers still made unfavorable (e.g., zero) offers when they had experienced a rejection before. Impulsivity control-and hence strategic decision making-has been shown to be important for proposers (Steinbeis et al., 2012). Furthermore, proposers in our study needed to attend to proportions at two levels, namely between the two trays on their side and the two dishes on one tray on both sides; in other words, children needed to attend to proportions of what they would get relative to the other child as well as to the proportions of what they would prefer between the two options available to them. This is a more challenging task of proportion understanding than that of McCrink and colleagues (2010), yet it is the most relevant for making fair divisions. Ours is the first developmental study to present proportional comparisons in this way. Future studies could explore the manner of how relative and absolute comparisons are presented; an interesting approach would be to present rewards of different qualities rather than quantities.

The 5-year-old proposers in this study did not play the mini-ultimatum game strategically, which would have involved being more generous in subsequent trials after experiencing a rejection. We did not reverse roles in order to avoid testing strategic behavior rather than other-regarding preferences. It is possible that children of this age would benefit from the experience of repeated rounds or role reversal to learn to make fairer offers and to reject unfair offers in the different games. Future research should aim to incorporate role reversal and repeated rounds to determine the role of immediate experience in shaping fairness preferences.

It is possible that proposals-and the rejection of these-are somewhat unfamiliar for younger children. Sharing is something that is encouraged by parents and teachers, but beyond the explicit sharing rules children have little practice with dividing resources and recognizing the appropriate response when faced with an unfair offer. However, children might be more familiar with taking things from others and responding to such theft. A variation of the ultimatum game in which proposers can steal a portion of responders' share might be more effective at eliciting sensitivity to unfair outcomes and the motivations behind them. Such an approach was recently applied to chimpanzees and bonobos (Kaiser, Jensen, Call, \& Tomasello, 2012).

Thus, this study shows that for 5-year-old children "fair" means an equal amount for all, with finer degrees of fairness considerations-that is, a deeper appreciation of the rationality of the choice behavior of the partner-developing only later in childhood. This accords well with the literature on children's understanding of distributive justice in which preschool children mostly think that everyone getting an equal amount is fair regardless of the amount of work they put into some enterprise, whereas older children take into account work effort and contribution to the enterprise (see, e.g., Damon, 1977, for a review). Preschoolers have an understanding of fairness, but there are a number of developments still to come for them to exhibit true fairness in adult-like ways.

\section{Acknowledgments}

The authors thank Roger Mundry for statistical advice as well as our research assistants, Mareike Sera and Eva Siegert, for administrative help and Iulia Gavriliu for the reliability analysis. Thanks go to Henrik Roethel and Manfred Ulrich for building the apparatus, and of course thanks go to all of the children who participated in the study.

\section{References}

Barmettler, F., Fehr, E., \& Zehnder, C. (2012). Big experimenter is watching you! Anonymity and prosocial behavior in the laboratory. Games and Economic Behavior, 75, 17-34.

Birch, L. L., \& Billmann, J. (1986). Preschool children's food sharing with friends and acquaintances. Child Development, 57, 387-395.

Blake, P. R., \& McAuliffe, K. (2011). "I had so much it didn’t seem fair": Eight-year-olds reject two forms of inequity. Cognition, $120,215-224$. 
Bolton, G. E., \& Ockenfels, A. (2000). ERC: A theory of equity, reciprocity, and competition. American Economic Review, 90, $166-193$.

Brownell, C. A., Svetlova, M., \& Nichols, S. (2009). To share or not to share: When do toddlers respond to another's needs? Infancy, 14, 117-130.

Camerer, C. F. (2003). Behavioral game theory. New York: Russell Sage.

Camerer, C., \& Thaler, R. H. (1995). Anomalies: Ultimatums, dictators, and manners. Journal of Economic Perspectives, 9, $209-219$.

Carpenter, M., Akhtar, N., \& Tomasello, M. (1998). Fourteen- through 18-month-old infants differentially imitate intentional and accidental actions. Infant Behavior \& Development, 21, 315-330.

Charness, G., \& Rabin, M. (2002). Understanding social preferences with simple tests. Quarterly Journal of Economics, 117, 817-869.

Damon, W. (1975). Early conceptions of positive justice as related to the development of logical operations. Child Development, 46, 301-312.

Damon, W. (1977). The social world of the child. San Francisco: Jossey-Bass.

Dufwenberg, M., \& Kirchsteiger, G. (2004). A theory of sequential reciprocity. Games and Economic Behavior, 47, $268-298$.

Falk, A., Fehr, E., \& Fischbacher, U. (2003). On the nature of fair behavior. Economic Inquiry, 41, 20-26.

Falk, A., \& Fischbacher, U. (2006). A theory of reciprocity. Games and Economic Behavior, 54, 293-315.

Farrell, J., \& Rabin, M. (1996). Cheap talk. Journal of Economic Perspectives, 10, 103-118.

Fehr, E., Bernhard, H., \& Rockenbach, B. (2008). Egalitarianism in young children. Nature, 454, 1079-1084.

Fehr, E., \& Schmidt, K. M. (1999). A theory of fairness, competition, and cooperation. Quarterly Journal of Economics, 114, 817-868.

Güroglu, B., van den Bos, W., \& Crone, E. A. (2009). Fairness considerations: Increasing understanding of intentionality during adolescence. Journal of Experimental Child Psychology, 104, 398-409.

Gurven, M. (2004). To give and to give not: The behavioral ecology of human food transfers. Behavioral and Brain Sciences, 27, 543-583.

Güth, W., Schmittberger, R., \& Schwarze, B. (1982). An experimental analysis of ultimatum bargaining. Journal of Economic Behavior and Organization, 3, 367-388.

Harbaugh, W. T., Krause, K., \& Vesterlund, L. (2007). Learning to bargain. Journal of Economic Psychology, 28, 127-142.

Hardy-Vallée, B., \& Thagard, P. (2008). How to play the ultimatum game: An engineering approach to metanormativity. Philosophical Psychology, 21, 173-192.

Henrich, J., Boyd, R., Bowles, S., Camerer, C., Fehr, E., Gintis, H., et al (2005). "Economic man" in cross-cultural perspective: Behavioral experiments in 15 small-scale societies. Behavioral and Brain Sciences, 28, 795-855.

Hook, J. G., \& Cook, T. D. (1979). Equity theory and the cognitive ability of children. Psychological Bulletin, 86, 429-445.

Jensen, K., Call, J., \& Tomasello, M. (2007). Chimpanzees are rational maximizers in an ultimatum game. Science, 318, $107-109$.

Kaiser, I., Jensen, K., Call, J., \& Tomasello, M. (2012). Theft in an ultimatum game: Chimpanzees and bonobos are insensitive to unfairness. Biology Letters, 8, 942-945.

Kogut, T. (2012). Knowing what I should, doing what I want: From selfishness to inequity aversion in young children's sharing behavior. Journal of Economic Psychology, 33, 226-236.

Lamba, S., \& Mace, R. (2010). People recognise when they are really anonymous in an economic game. Evolution and Human Behavior, 31, 271-278.

Levine, D. K. (1998). Modeling altruism and spitefulness in experiments. Review of Economic Dynamics, 1, 593-622.

Loewenstein, G. F., Thompson, L., \& Bazerman, M. H. (1989). Social utility and decision making in interpersonal conflict. Journal of Personality and Social Psychology, 57, 426-441.

McCrink, K., Bloom, P., \& Santos, L. R. (2010). Children's and adults' judgments of equitable resource distributions. Developmental Science, 13, 37-45.

Meltzoff, A. N. (1995). Understanding the intentions of others: Re-enactment of intended acts by 18-month-old children. Developmental Psychology, 31, 838-850.

Moore, C. (2009). Fairness in children's resource allocation depends on the recipient. Psychological Science, 20, 944-948.

Mundry, R. (1999). Testing related samples with missing values: A permutation approach. Animal Behaviour, 58, $1143-1153$.

Olson, K. R., \& Spelke, E. S. (2008). Foundations of cooperation in young children. Cognition, 108, 222-231.

Rabin, M. (1993). Incorporating fairness into game theory and economics. American Economic Review, 83, 1281-1302.

Rakoczy, H., Warneken, F., \& Tomasello, M. (2007). "This way!” "No! That way!” 3-Year-olds know two people can have mutually incompatible desires. Cognitive Development, 22, 47-68.

Rochat, P., Dias, M. D. G., Liping, G., Broesch, T., Passos-Ferreira, C., Winning, A., et al (2009). Fairness and distributive justice by 3- and 5-year-olds across seven cultures. Journal of Cross-Cultural Psychology, 40, 416-442.

Sally, D., \& Hill, E. (2006). The development of interpersonal strategy: Autism, theory-of-mind, cooperation, and fairness. Journal of Economic Psychology, 27, 73-97.

Steinbeis, N., Bernhardt, B. C., \& Singer, T. (2012). Impulse control and underlying functions of the left DLPFC mediate agerelated and age-independent individual differences in strategic social behavior. Neuron, 73, 1040-1051.

Sutter, M. (2007). Outcomes versus intentions: On the nature of fair behavior and its development with age. Journal of Economic Psychology, 28, 69-78.

Takagishi, H., Kameshima, S., Schug, J., Koizumi, M., \& Yamagishi, T. (2010). Theory of mind enhances preference for fairness. Journal of Experimental Child Psychology, 105, 130-137.

Tingley, D. H., \& Walter, B. F. (2011). Can cheap talk deter? An experimental analysis. Journal of Conflict Resolution, 55, 996-1020.

Warneken, F., Lohse, K., Melis, A. P., \& Tomasello, M. (2011). Young children share the spoils after collaboration. Psychological Science, 22, 267-273.

Warneken, F. A., \& Tomasello, M. (2006). Altruistic helping in human infants and young chimpanzees. Science, 311, 1301-1303.

Warneken, F. A., \& Tomasello, M. (2007). Helping and cooperation at 14 months of age. Infancy, 11, 271-294.

Wellman, H. M., Cross, D., \& Watson, J. (2001). Meta-analysis of theory-of-mind development: The truth about false belief. Child Development, 72, 655-684. 